\title{
Technology and Sociomaterial Performation
}

\author{
Adrian Yeow ${ }^{1}$ and Samer Faraj ${ }^{2}$ \\ ${ }^{1}$ SIM University, Singapore \\ adrianyeowyk@unisim.edu.sg \\ ${ }^{2}$ Desautels Faculty of Management, McGill University, Montreal, Quebec, Canada \\ samer.faraj@mcgill.ca
}

\begin{abstract}
Organizational researchers have acknowledged that understanding the relationship between technology and organization is crucial to understanding modern organizing and organizational change [1]. There has been a significant amount of debate concerning the theoretical foundation of this relationship. Our research draws and extends Deleuze and DeLanda's work on assemblages and Callon's concept of performation to investigate how different sociomaterial practices are changed and stabilized after the implementation of new technology. Our findings from an in-depth study of two ambulatory clinics within a hospital system indicate that "perform-ing" of constituting, counter-performing, calibrating, and stratifying explained the process of sociomaterial change and that this process is governed by an overarching principle of "performative exigency". Future studies on sociomateriality and change may benefit from a deeper understanding of how sociomaterial assemblages are rendered performative.
\end{abstract}

Keywords: sociomateriality, assemblage, performation, healthcare IT.

\section{Introduction}

New ways of organizing are constantly emerging from different combinations of technology and organizational features and lead to renewed attention to the role of technology as a critical thread to the changing fabric of organizations. Thus, there is considerable interest among organizational researchers to understand and theorize the relationship between the social and the material whenever technology meets organizing [1-3]. Under the rubric of "Sociomateriality", an emerging research project within the fields of information systems and organizational studies has put forth a relational perspective between organizations and technology or the social and the material that challenges the privileged role of the human actor [3, 4].

One of the main contributions of sociomateriality is that it helps researchers recognize the importance of the mutual relationship between the social and the material. In fact, all contemporary organizational practices can be seen as constituted by an array of sociomaterial agencies [4]. It has also introduces a new vocabulary (e.g., affordance, entanglement, imbrication scaffold) as a way to express and discuss these mutuality relationships $[5,6]$. However, this invitation to embrace a relational ontology is difficult to embrace given the traditional social science emphasis on objects rather 
than relations, on describing object qualities rather than its evolution [2]. More importantly, this theoretical relationship of organization and technology has significant implications for our understanding of organizational change following the implementation of new technology.

Our research study contributes to this emerging stream of work by developing a performation lens based on Deleuze, DeLanda [7] as well as Callon [8] and his associates [9] work. We applied this lens in an empirical case to deepen our understanding of the perfomation process and to answer our research question: How are sociomaterial practices changed and stabilized after the implementation of new technologies? Our findings suggest that the change process of sociomaterial practices is characterized by four "perform-ing" of constituting, counter-performing, calibrating, and stratifying, and is governed by an overarching governing principle of "performative exigency". After developing our grounded findings, we join them with our new lens to propose a rich set of vocabulary to understand the evolving practices and provide new theoretical opportunity to deepen understanding of how sociomaterial assemblages are made performative as well as organizational consequences of the evolved assemblages.

\section{Understanding Sociomaterial Change from a Performation Lens}

The performation lens draws from work by Deleuze and Guattari [10], DeLanda [7] and Callon [8] and his associates [9]. We specifically consider two key concepts that underlie this lens - the concepts of assemblage and performation - and how they compare and contrast with existing work on sociomateriality.

Like existing views on sociomateriality $[4,11]$, this lens adopts a relational ontology and argues agency is produced by specific sociomaterial configuration or "assemblage". According to Deleuze and DeLanda, an "Assemblage" is an arrangement and combination of heterogeneous components, including discursive (e.g. techniques, logics, ways of working), social (e.g. relationships, structures) and material artifacts interrelated to one another in such a way that brings about evolving patterns of actions. This view has been incorporated in part within the writings of Michel Callon, Karen Barad, Lucy Suchman, Andrew Pickering and Wanda Orlikowski.

However, there are several important nuances of Deleuze and DeLanda's [7] notion of assemblage that have important implications for existing sociomateriality lenses. First, Deleuze and DeLanda proposed that the components that constitute assemblage have inherent properties apart from the assemblage. In that sense Deleuze and DeLanda proposed that assemblages are not ontologically one and its components are independent of the assemblage as per Barad's agential realism view. At the same time, Deleuze and DeLanda point out that each component has different relational capacities. The components' capacities, whilst based on its properties, depend in part on what other components and how they are related to each other. Using the notion of relational capacities, they argue that social realities exist not at the level of the component as proposed by others [12-14] but at the assemblage level, where individual components are interrelated to form the assemblage. At the level of the assemblage, the overall capacity of the assemblage is irreducible to its individual components and 
its properties; instead the assemblage's capacity is hard to determine a priori given that it depends on how each component's relational capacity is activated with other components and whether what other components are present. In other words, while the assemblage depends on its constituent components the properties of the components do not determine the whole assemblage, as it is partly dependent on how they are related together that activates different relational capacities. Thus as an example, a microcomputer has many properties by itself - it helps records, process, stores, etc. However, when put in a specific assemblage composed of different other components, different relational capacities (based on its inherent properties) may be exercised and activated, which in turn may lead the assemblage to perform differently. Thus a standalone computer related or installed with word processing program versus the same computer connected to a printer would lead to two different assemblages performing different practices - the former simply word processing while the latter the ability to process and print documents. Callon [8] referred to this principle in this way - assemblages are endowed with different capacities of acting depending on how heterogeneous components are adjusted and configured to one another.

In this way, Deleuze and DeLanda's assemblage synthesizes some different views held within existing sociomateriality research in that the relational ontology is important; it is important to consider the sociomaterial assemblage and its capacities and agency in specific time and place; yet at the same time, it is possible to understand assemblage by considering the assemblage's individual components and their attending relationships, but to consider that holistically and from a relational viewpoint as the assemblage's capacities are dependent on its relationships with other components within the assemblage.

Second, Deleuze and DeLanda's heterogeneous components are not limited to human actions or social structures and material artifacts. They were explicit in including other components that were typically not considered in sociomaterial studies - components that include symbols, expressions, rhetoric, discourse, logics, and ideas. This is important given that the motivations and reasons why actors and artifacts behave in certain ways and have specific properties are often found in these expressive components. This is especially highlighted in Callon [8] and associates' [9] work on economic sociology, which used Deleuze and DeLanda's assemblage to explicate how performances of economic realities are linked to economic theories via a host of actions and artifacts. Thus, Deleuze and DeLanda's assemblage complements the notion of affordance in sociomateriality by pointing to these discursive components as sources of perceptions of affordances and constraints.

Finally, Deleuze and DeLanda see the relations among the components within the assemblage as contingent and tenuous and that parts of the assemblage could easily be extracted from one assemblage to another creating different interactions, relationships and assemblages. This dynamism in their formulation of assemblages therefore aligns with the process of becoming that some sociomaterial research has focused on $[15,16]$. Because assemblages are dynamic, it behooves us to understand the process by which assemblages emerge, change, and become stable. Yet at the same time, this formulation of assemblages does not just focus on the patterns and configuration of components, but rather, it is more concerned with how the new assemblage is rendered performative and its implications for organizing. This particular focus leads us to the second main concept - performation. 
The notion of performation refers to the assembling process through which existing or new sociomaterial assemblages are rearranged and reconfigured so as to render it performative in the presence of preexisting social and material contexts [17, 18]. While Deleuze and DeLanda have broadly theorized on this processes (process of stabilizing and destabilizing assemblages), we turned to Callon [8], MacKenzie, and their associates' [9] empirical work within the field of economic sociology to develop the notion of performation.

Callon argued that while it is important to study the performativity of economic assemblages, it is more important to understand how these assemblages are rendered performative (made to perform) or the process "performation" (coined by Callon). This view is in line with research in science and technology studies that have looked at the work required to configure and make experiments work [e.g., 16]. Some of those studies have characterized the process as "mangling" - through which hybrid practices emerged with performances fixed neither wholly in the material or social entities [16]. Others point to the emergent configurations of expertise, skills, work procedures, practices and tools that serve to support the organization's performance [19]. This type of work as described in this stream of work tends to be "invisible" in that they are work that make and keep technologies and assemblages working $[18,20]$.

In general, Callon and associates' research agree with them in that performation is an emergent and dialectical process that typically takes place in the background. They tend to highlight the collective actions of not just actors but also material and discursive components in creating, changing, and stabilizing assemblages. In other words, performation is practical, performative as well as discursive [18, 21]. It attempts to describe the dynamic actions, fluid gatherings, and emergent interactions by which assemblages are incrementally linked and reconfigured so as to render them performative.

The performation process may go beyond a single sociomaterial assemblage to include other performances - that is, work that joins different assemblages' performances together seamlessly $[18,22,23]$. Thus another key point when considering the process of performation is the fact that sociomaterial assemblage is never performed in abstract or introduced tabula rasa in organizations. Instead, in a performation process, we have to explicitly recognize that sociomaterial assemblages perform with or as part of another set of sociomaterial assemblages in the same site of production [18]. The different preexisting assemblages serve as a "solid and obdurate" backdrop to new or changed assemblages as they may provide opportunities or limit and constrain the process by which new or changed assemblages evolve [18].

Finally, the performation process also leads us to evaluate and judge the outcomes of these actions from a performative exigency [8]. In other words, one would evaluate the "success" of the performation process given how well the new or changed assemblage performs, i.e., "performative exigency". The performative exigency provides the basis for the assemblage to either continue with the performation process such that additional work is required to be done (i.e., it is not performing well or as intended) or to begin stabilizing the changed assemblage. Thus the performation lens not only looks at the assemblage and how it changes, e.g., through the introduction and use of a new technology; it also considers the performative aspect or how the changed or new assemblage is performing. 
Put together, the performation lens provides us with two important concepts to help better understand sociomateriality and change. The concept of assemblage - as an ontological-epistemological construct - helps to resolve some of the current tensions in sociomaterial research. While it focuses on organizational and social realities as assemblages, it does help us see that they are constituted by interrelated heterogeneous components. It also considers such assemblages as dynamic entities that could be changed as these components and relationships are reconfigured or even moved to other assemblages. Here the concept of performation helps to conceptualize this becoming process as one characterized by invisible work - work that involves pragmatic, collective actions enacted by the material, social and discursive components. Unlike current sociomateriality's focus on the patterns of interactions [15, 24], the performation lens considers the assemblage as well as its interior relations. Further the performation lens explicitly considers how the assemblage interacts within the context of other existing assemblages found within the site of productions. Finally, the performation process is in turn shaped by the performative exigency; in other words, the relative success of the assemblage performances determines the point at which the emergent assemblage begins to stabilize.

While the performation lens has provided us with a vocabulary to describe these issues, more work needs to be done to ground these concepts and deepen our understanding of the perfomation process by which new sociomaterial assemblage are made to work. Specifically, we still are unsure of the different "perform-ing" work that are required, the conditions leading to the "perform-ing" work, as well as the organizational implications of such sociomaterial changes. Our in-depth study of an EMR implementation across two different clinics attempts to provide insights into this process, specifically focusing on understanding the "perform-ing" and the conditions in which they are undertaken and how that consequently shape the final outcomes. We discuss the setting and our methods next.

\section{$3 \quad$ Methods and Setting}

\subsection{Research Approach}

We conducted an in-depth, longitudinal case study analysis of an EMR system implementation project [25]. We provide a brief overview of the setting and EMR project before describing the research methods in the following section.

\subsection{Research Setting and Background}

The two clinics belong to Centralsys, a pseudonym for a public state-wide hospital system on the East Coast of the United States. Centralsys owns and manages seven hospitals and health systems that together account for 1,800 beds. The EMR implementation process for Metro and Suburb took 14 months to complete. It involved over 65 full-time EMR project team members. All in all, the EMR system go-live was successfully launched with no major technical glitches. 


\subsection{Data Collection}

The study took place between July 2007 and March 2009. During this 18 monthperiod, we spent a total 12 months of on-site observations, interviews and archival data collection at the two clinics and project management sites. Our involvement with the project covered three phases: the first phase lasted three months and included the EMR process design and implementation planning activities (July to September 2007), the second phase lasted eight months and was focused on implementation and initial use of the EMR system in both clinics (October 2007 to May 2008), and the third phase lasted two months and was focused on understanding how work practices had evolved after the clinics had used the EMR system for more than one year (February to March 2009).

We relied mainly on field observations of work practices in each clinic as well as observations of project meetings where designs of new practices were discussed. We also conducted in-depth interviews with the clinic staff and Centralsys project team to understand how the EMR practices are performing and to reflect on evolution of problems and their consequences in the EMR practices. In total, we were in the field for 91 days: 14 days at the EMR project management site, 47 days at Metro and 30 days at Suburb. We wrote up around 381 pages of field notes and conducted 95 formal interviews with EMR project team members, Centralsys management, and all the staff in the two clinics. We also collected nearly 2,000 archival documents including e.g., system requirements, standard operating procedures for the different clinic practices before and after the EMR.

\subsection{Data Analysis}

Our data analysis was focused on individual practice within each clinic. Practice is defined as actual patterns of activities and social interactions among organizational actors as they go about accomplishing specific organizational goals [26]. Using our observations of work as well as discussion during project meetings, we decided to focus on one practice (due to space constraints) - lab reporting - for our in-depth analysis. We chose this practice for three reasons. First, this practice was critical in its respective domain of work. Lab reporting form the bulk of follow-up patient care [27]. Secondly, it was significantly influenced by the new EMR system and therefore provided important data regarding its effects. Finally, based on our interviews with the clinic management and project staff, this practice had significant operational issues prior to the EMR implementations.

For our in-depth analysis, we first carefully compared the observed practices across clinics and then within clinics across time. This helped us determine how they were similar or different before the EMR implementation and how they had changed after the EMR implementation. Next, we compared the practice with those that were planned and documented in the EMR manuals and user requirements. This helped to surface how the post-EMR practice compared with the planned practice.

We used an inductive approach [28] to analyze how and why those differences in practices were observed. We coded the interviews, minutes, and observations that referred to implementations issues or problems related to the three practices that had surfaced during the implementation phase (the basis for "counter-performing"). Using 
these data, we constructed a composite narrative of the issues within the practice. With the issue narratives as conceptual anchors, we proceeded to first trace backward in time to understand the sources of these issues (the basis for "constituting") and later forward in time to understand the collective actions to solve and consolidate the new emergent practices (the basis for calibrating and stratifying). By iterating and comparing the practice's narratives with extant literature, we were able to identify the different categories of perform-ing and how they were related over time.

\section{$4 \quad$ Findings}

Our findings are presented in two sections. The first section provides detail of the existing issues surrounding the lab resulting practice at Metro and Suburb and how the implementation of a new EMR system led to different emergent new practice. The second section traces the sociomaterial change process from the performative assemblage perspective to explicate how and why this different emergent practice emerged.

\subsection{Emergence of Different Metro and Suburb Practices with EMR}

First, we briefly describe the site of production and the lab resulting practice. Metro clinic ("Metro") is a family practice clinic with six physicians, five medical assistants, nine support staff (front-desk, phone operators, referral coordinator and medical records) and one clinical manager serving 23,000 patient visits per year. Suburb clinic ("Suburb") provides family care services similar to Metro and has three full-time physicians, three medical assistants, four support staff, and one clinical manager, handling 8,600 patient visits per year.

Lab resulting practice incorporates all aspects of communication among physicians, support staff, laboratory and patient regarding the results of a patient's laboratory tests. A physician may order a lab test as a part of general assessment, to confirm a diagnosis, or to monitor drug therapy. The results of these tests must be appropriately communicated and followed up in order to ensure safe and effective care. As Metro had an on-site lab facility operated by an external lab provider, Metro's patients are sent directly to that lab for their lab works. Metro physicians therefore receive their lab results directly from the on-site lab office. In contrast, Suburb does not have an on-site lab. When a Suburb physician orders a lab test, the patient are given the lab test orders and find an external lab to conduct the tests. Patients usually choose one of the two larger laboratory test providers. The external lab will fax or mail the results to Suburb's physicians once the tests are conducted.

Overall, the goal of the physicians' lab resulting practice is to ensure that lab results are properly diagnosed by ordering physicians and communicated to patients in a timely and appropriate manner given the outcomes of the tests. But these practices were highly personal as they depended on each physician's preferred follow-up routine (Minutes from Physicians Advisory Group meetings). While some physicians attended to medically urgent lab results directly with the patient and delegated nonurgent cases to the medical assistants, other physicians would deal with all lab results personally. It also differed at the clinic level. At Metro clinic, they had implemented a policy that all covering physicians were notified of lab results even if they had not 
ordered them, while at Suburb clinic this was not so. Due to the large patient load, Metro physicians do not always follow up on reminders to advise patients of normal lab results, so they decided to inform all patients to call the clinic for results. At Suburb, the call back process is determined by the physician on a case-by-case basis. In some cases the medical assistant may be responsible for following up with the patient, while in other cases the patient may initiate the call.

The new EMR lab resulting practice performed well in Metro given that the link between its EMR and onsite lab provider's lab resulting system was properly interfaced. Suburb, however faced more problems with the new practice, as the lab providers were not onsite and the technical interfaces were not properly connected. Differing practices of Suburb's lab providers also contributed to ongoing contradictions of missing or lab results that are linked to existing lab orders in the system.

\subsection{Process of Sociomaterial Change - Performativity Exigency on New Assemblage}

In our analysis, we traced the sociomaterial change process and explicated four interrelated "perform-ing" surrounding the new assemblages: constituting, counterperforming, calibrating, and stratifying.

The first perform-ing was "constituting assemblage" - how the EMR artifact was constituted with components of the existing assemblages for the practice. Essentially, it focuses on the perform-ing of external actors i.e., the Centralsys and clinics' management, as they attempted to add a new technological component (in this case the EMR) in existing assemblages. In this "perform-ing", external actors had to consider how the new technological component is made a part of the whole, so as to combine it with other relevant components and to express that in a coherent way. In other words, to "constitute" the new component as part of the assemblage implies changes in the relations, components and boundaries of the assemblage, thereby creating new assemblages in the sites of production.

The expressive associated with the EMR lab resulting assemblage was one of "standardization" i.e., Lab resulting practice was redesigned so that the EMR integrated the clinics lab processes with the lab providers' systems. In the new EMR assemblage, work would be standardized so that all physicians would associate all lab orders with diagnosis and automatically send it electronically to the respective lab provider via the EMR system. All lab results would be electronically routed from the lab system back to the EMR inbasket following standardized routing rules set by Centralsys management. According to these rules, all normal lab results would be routed only to the ordering physician while abnormal results would be routed to all physicians in the clinic. This would allow for prompt follow up of abnormal results even if the ordering physician was off duty. In turn, the physician may choose to directly contact the patient concerning the results or may send this off to their medical assistants for other follow-up actions. This assemblage would be used in both clinics regardless whether they had an on-site lab or not.

This second "perform-ing" was "counter performing", which refers to how components and relations of the constituted assemblages breakdown leading to "counterperformances". Some counter-performances centered on contradictions within the assemblage, e.g., problematic relations or components. For lab resulting practice, the 
increased interactions between medical assistants and physicians for lab resulting created confusion among the Metro's physicians and medical assistants. Due to the rotation of medical assistants at Metro clinic, a mechanism had to be developed to ensure that lab results were followed up consistently. A "message pool" in the EMR system allowed inbasket requests to be sorted by physician's name. However, given the high volume of lab reports in the inbasket messages, the message pool soon proved to be highly unmanageable. Problems such as overlooking, or multiple medical assistants working on a single follow-up, frequently occurred.

Others counter performances centered on contradictions between assemblages. Some were contradictions between two new assemblages while others involved the new and existing assemblages. The lab resulting situation in Suburb was illustrative of contradictions between the new assemblage and existing assemblages. On the one hand, there were ongoing technical problems in the integration of the EMR system and the external lab systems. Unlike Metro who was interfaced with one system, i.e., the on-site lab provider system, Suburb had to be interfaced with two lab systems as their patients could choose from either lab provider. The Centralsys project team had stabilized the interface with the first lab provider system but had not anticipated the complications arising from integrating with the second lab provider. Part of the complications was that a lab order with two or more tests would have each test result sent back to the physician as separate reports in their in-basket. As one of the Suburb physician explained, the different lab test reports coming back separately (and on different timings) confused the ordering physician since they have to make diagnosis not only one test result but a set of test results.

On the other hand, how Suburb's patients interacted with the lab providers also created problems. Specifically, patients who go to an external lab provider (as in Suburb's case) are issued with a paper lab order slip while the electronic order is directly sent to the lab provider's system. When patients present themselves at the lab, sometimes the lab provider's staff unknowingly entered in a new lab order during registration. The lab technician who actually carries out the order would encounter two lab orders - one that was electronically transferred and one that was created during registration. This resulted in cases where the Suburb physician would receive two results or no results depending on whether the lab technician checked off on both the lab orders or checked off on the "wrong" lab order. In other cases, lab orders had timerelated restrictions - some were activated only after a certain time frame (e.g., patients need to have the lab done one month after the visit) or in certain cases, the patient forgot to have the lab done within two months and the lab provider system automatically removed that order from its system. In these cases, patients may end up having the lab done - but as an unsolicited order. The results for unsolicited cases do not come back to the ordering physician as an electronic in-basket message but as a paper lab result. Thus it resulted in contradictions and counter-performances between the new EMR lab resulting assemblage and the existing lab order assemblages.

Calibrating perform-ing refers to how collective actions were enacted by different actors to repair and/or consolidate the new relations among different components within assemblages in reaction to counter-performances encountered. One series of calibrating "perform-ing" involved rearranging problematic relations or components within the assemblage in order to reduce or remove the counter-performances. Some of these calibrating "perform-ing" eventually led to changing these problematic parts. 
For the lab resulting case in Metro, as discussed above, one of the initial design in view of the rotating medical assistant-physician policy was to utilize the message pool function in the EMR system. The counter-performances revealed that this new arrangement of a message pool did not work with the rotation policy. Centralsys ambulatory care operational leadership and Metro's management realized, however, that Suburb did not have such issues as they used a fixed physician-medical assistant arrangement. The calibration was to change the existing relationships among the medical assistants and physicians and Metro's own policies. This new arrangement assisted to reduce the confusion as medical assistants knew which in-basket instructions and messages to follow-up and also built up better coordination and communication between physicians and their medical assistants.

The other series of calibrating "perform-ing" was creating and re-establishing of new boundaries of the assemblages by adding or changing components and relationships across assemblages. This was mainly targeted at counter-performing contradictions between assemblages. We observed this mainly in Suburb's case. The first set of calibrating in Suburb was to re-establish the boundary of the lab resulting assemblage with the external lab provider systems that had been counter-performing due to technical interface problems. The Centralsys' project team spent nearly a year working closely with the lab providers' technical team to troubleshoot where the interfaces had problems in order to solve the multiple reporting interface issue.

This was however only part of the problem as discussed above. The next series of calibrating, which was done in parallel with the technical calibrating, involved clarifying and changing relations in work processes across the two assemblages. Specifically, the Centralsys team worked closely with the lab providers to clarify their work processes to deal with the issues of repeat and unsolicited lab results. However, Suburb continued to face problems when patients did not cooperate e.g., forgot their lab appointments and went after the lab order period etc. In such cases, Suburb physicians continued to rely on paper-based reports as part of the lab resulting practice.

Stratifying "perform-ing" refers to actions of human actors within the assemblages as well as actions enacted through the assemblages that occurred after the new assemblages are rendered performative again. However these new performances by the assemblage are not completely "optimal" or designed - there remained some minor issues here and there. Actors within the assemblages thus attempted to "smoothen" these issues through discourses that involved expressive components (e.g., efficiency concepts, patient-centricity) to codify and consolidate the new assemblages and their performances. At the same time, EMR assemblages performed a new form of accountability - a different form of "structure" - that the actors find themselves drawing upon as part of their practices. Together through intentional discursive actions that enrolled expressive components and emergent 'accounting' of the new assemblage on daily practices, the new EMR assemblages became stabilized.

Part of stratifying was to codify the assemblage by foregrounding the performances as one of the accepted practices via linking it to organizational expressive concepts like "efficiency" and "improvements" while shifting the new technological component to the background. For example the Director of Centralsys Ambulatory Care Operations pointed out that the new assemblage was working "more seamless" as earlier problems were no longer issues. 
Similarly, physicians and other clinic staff made reference linking the new assemblages with patient-centric care and efficient workflows. For e.g., Metro's Dr. S tried explained in detail how the EMR-based lab resulting assemblage made his lab resulting performance "more efficient" by making information readily available.

Another part of stratifying was to discursively smooth over the minor issues that continued in the new assemblages' performance. For e.g., management and users admitted that some issues were distracting but expressed a need to compromise for the sake of how other parts of the assemblages were working. For example, in Suburb's lab resulting case, the practice manager agreed that things have improved albeit with specific issues for e.g., lab results not returning together or when new physicians joined the practice later.

Things have gotten a little easier with the lab system as people are more familiar. [We had some] challenges with the two new providers, [they] threw us a [into a] loop. But now we have fallen into a routine with the systems. (Suburb Clinic Manager)

On the other hand, we noted that the ongoing performances of the new EMR assemblages as daily practices had introduced a new performance - a new form of accountability among those involved in the assemblages [29]. Part of the emergent accountability involved individual actors defining their identities and roles vis-à-vis other actors linked within the assemblage. The definition of identities and roles via the system so as to perform new accountability was especially salient in the case of medical assistants and physicians. In particular, the management claimed that the new lab resulting assemblage had aligned the medical assistants' actual work with the "ideal" medical assistant role and identity. Based on our data, we noted several key changes the EMR artifact brought to the new assemblages, which catalyzed the new accountability among different actors' and their roles. On the one hand, the new EMR system conferred new visibilities to the actions of individual actors and made it possible for other actors to compare their actions with other actors. On the other hand, the new EMR system enabled the focal actor and others to assess and evaluate their performances and react accordingly.

With regards to the latter point, we noted that nearly after a year into the system some of the medical assistants did get over the initial perception that EMR was "more work" to see the entire EMR as an important part of how they get their work done with the physicians. This brings us to the next aspect of stratifying, where actors now consciously or unconsciously drew upon the ongoing practices to perform new accountability. Thus, medical assistants and physicians have increased mutual accountability as a result of performing the new lab resulting assemblage. The assemblage's performance through the EMR system helped to better allocate responsibilities between the physicians and medical assistants.

The new accountability was drawn upon by the Centralsys' and clinics' management to measure, compare, and intervene with the assemblages' performance, in a very specific manner. For example, the clinic directors can get reports enumerating, summarizing and comparing the turnaround of lab resulting performances or scheduling output. Thus the different assemblages' performances are made accountable to management supervision and scrutiny. These reports through the EMR system enabled the management to 
drill-down to how each actor in the assemblage is contributing to the overall performance - e.g., particular physician or medical assistant's number of uncompleted inbasket messages and orders.

\section{Discussion}

Recently scholars under the rubric of sociomateriality have suggested that we need to take a relational perspective between social and material to understand organizations and change. Drawing upon Deluzian and DeLanda's [7] ontology, we sought to develop a potentially new lens and theoretical vocabulary - the performation lens - to understand how these sociomaterial assemblages perform within and across organizations. In particular, we used this performation lens to explore the dynamics of change when existing sociomaterial assemblages are faced with a new technology.

Principally, the performation lens contributes by making salient the role of collective actions by heterogeneous components - or "perform-ing" - in rendering the changed assemblages performative. From our findings, we identified four interrelated "perform-ing": constituting, counter-performing, calibrating, and stratifying. First, constituting explained how new assemblages emerged and are implemented i.e., actors draw on the expressive components such as new organizational goals and link them to the new IT artifact, which is then made part of the reconfigured assemblage. However, when these constituted EMR assemblages are implemented, counterperforming occurs as new relationships and new components breakdown within the new assemblages and between assemblages. Next, counter-performing becomes the targets for calibrating perform-ing, which involved rearranging problematic relations and/or components or adding relations and/or components across assemblages. Finally, as calibrating perform-ing renders the assemblages performative again, stratifying perform-ing emerged. Stratifying included discursive actions by human components that codified and consolidated the new assemblages as well as emergent performances of accountability that drew upon these assemblages.

Below, we elaborate on the contributions and significance of the performation lens in three different areas. First, we discuss how the performation process with its attending perform-ing helps us grasp more precisely the way assemblages are changed and rendered performative. These perform-ings builds on current sociomaterial research that has looked at how social and material are entangled together by expanding the scope and span of what and who are involved in this "invisible" work [18, 20]. Second, our analysis of counter-performing and calibrating revealed the process is not random but governed by an overarching pragmatism. We term this governing principle as "performative exigency" as the basis for determining the "success" of changed assemblages [8]. Third, we examine the organizational consequences of the evolved assemblages. Our findings show that beyond the obvious changes to each assemblage/practice across the two clinics, we noted that the new assemblages were associated with different performances of accountability [29, 30]. 


\subsection{Performation and Perform-ing}

Research on how social and material or human and artifacts become interwoven and entangled have often characterized it as a dialectical process involving tensions between single human actor (e.g., researcher or programmer) and a particular material artifact (e.g., laboratory apparatus or software program) $[16,31]$. The process is driven by the resistance and accommodation experienced by the actors as they worked with the artifacts. Some of the recent studies have expanded this beyond human actions to include material agencies and how the two agencies become "imbricated" over time [15].

Our findings concerning the different perform-ing within the performation process extend this stream of research in several ways. First, unlike the current research that focuses on single user-artifact interactions, the perform-ing show that assemblages typically involved multiple groups of actors interacting with each other, sometimes directly and sometimes mediated by multiple material artifacts. Furthermore, the different actors are distributed across time and space. As shown in Callon and associates [8] study on the performativity of economics as well as in some recent work within the IS domain [31], this distributed multiplicity of actors means that it is not sufficient to consider individual user-artifact resistance and accommodation to understand how assemblages change and are stabilized. In fact, our study shows that perform-ing often involved resources and capabilities beyond that of individual components. Instead, our performation process shows the change process entails collective actions by different groups $[8,32]$. These collective actions involved human actors with different capacities e.g., local users, project team members as well as hospital management working either in parallel or together to understand where the issues were and then putting in place strategic interventions. Further, some of these collective actions involved actors not directly using the system e.g., clinic management and project team. These actors enrolled material and discursive components as part of their managing, planning, and framing strategic interventions and material changes (e.g., policy change and interface development work) that were critical to rendering the assemblage performative. Thus unlike earlier studies of sociomaterial change, the performation lens enables us to take a wider analytical view beyond the immediate material and social interactions, so as to take into account the different types of collective work enacted by multiple groups of heterogeneous components.

Second, the perform-ing in the performation process provided a more nuanced appreciation for using a relational perspective to understand sociomaterial change. As shown in our findings as well as in recent sociomaterial work [5, 31], while each component may have their intrinsic properties, how "flexible" they are is are not based on those intrinsic properties alone but on how they are related with other components as well as on whether certain components are present or absent. For example, medical assistants are trained to use computer systems as part of their work and the EMR system supporting lab resulting was a piece of stable software. Yet when these two components were placed in the new lab resulting assemblage, the additional components such external lab systems changed the dynamics of the assemblage so that the medical assistant-EMR system link became problematic. In other words, the 
performation process is more than just failure of systems or user resistance. It is about understanding the emergent, situated dynamics among the multiple relations within and across assemblages.

Third, the performation process also bring to fore the role of other existing assemblages. Our performation and perform-ing argue that existing infrastructures plays a more active role than just acting as a "context" for current actions [33, 34]. Instead, we show that existing infrastructures are relational [35] and performative. In our constitutive and counter-performing perform-ing, we show that new assemblages are always linked to one or more assemblages [33, 34]. Furthermore, Callon and associates [8] mooted the idea that sometimes, in order for a focal assemblage to perform it has to ensure that other assemblages surrounding it co-performs. In other words, existing infrastructure or assemblages also shape how an assemblage is changed in terms of how it assists with or co-perform with the focal assemblage. This was well illustrated in our Suburb's lab resulting case where Suburb's new EMR lab resulting assemblage faced significant problems because their interfaces with the external lab system (an assemblage) were not performing correctly. The lab resulting assemblage also faced issues with how external lab providers' performed their lab tests and lab result data entry as the way they entered the data had important implications for how Suburb's physicians received the lab results. Thus, performance issues of sociomaterial assemblages may be due to how they are related with components from existing assemblages rather than issues emanating from the focal assemblage's own failings. Our performation view argues that we need to move one step beyond just taking into account existing structures and systems as those discussed in extant literature, but that we should include them into our analysis as active co-performing assemblages.

Finally, our performation process also speaks to a gap currently in most of sociomaterial research, i.e., how does changed sociomaterial assemblages become stable? Current studies of imbrication seem to imply an ongoing linear process of change without clearly explaining how and when imbrications end [12]. Other studies from Barad's [11] agential realism perspective tend to begin their analysis of a changed sociomaterial assemblage and focus on its consequences [5]. Our findings provide some insights into the perform-ing - Stratifying - that helped stabilize those changed assemblages. As discussed in our findings, stratifying involved actors enrolling discursive components to codify the assemblages as performative and actors consciously or unconsciously drawing upon the performed assemblages in enacting new accountability. Through the discourse and performances of new organizing structures, we found that the new assemblage in the two clinics became reified and taken-forgranted. The discursive aspect of stratifying attempts to make consolidate the new assemblages by linking it with a certain organizational logic or concepts (efficiency, patient-centric) while smoothing out "lumps" in the new assemblages [7]. In sense, the changed assemblage's ongoing ability to perform is highlighted by these discursive components thus suggesting a degree of rigidity of the new assemblages. This insight lends itself to future research that scholars within the domain of discourse research have also called attention [36]. With regards to new accountability performed as part of the reification of assemblages is discussed in the later section. 


\subsection{Performative Exigency}

With regards to the idea of performative exigency, we argue that this principle extends current research on IT-enabled change. First, most IT-enabled change research has focused mainly on the "here and now" and do not provide more insights to the overarching change trajectory besides informing us that such changes tend to be ongoing $[37,38]$. Second, some IS research that adhere to actor-network theory proposed that such changes are often emergent, random and subjected to "drift" as improvised uses and other unpredictable behaviors or interdependencies between human and material agencies emerge [39-41]. From our study, we argue against characterization of socimaterial change as random. We proposed that the performation process is governed by an overarching governing principle i.e., "performative exigency"; this pragmatic principle, which flows from the underlying performative approach, forms the basis for evaluating and driving the change process. The performative exigency therefore argues that the goal of any sociomaterial change is to cause the assemblage to perform better. Consequently, this performative exigency also sets the bounds to how the assemblage evolved. For example, in constituting the new assemblages, actors often enroll the efficiency principle, which is grounded on improvements of performances. Sometimes, actors may relate certain changes to current challenges to the performance of existing assemblages. More importantly, we see the performative exigency driving the calibrating perform-ing, where the overarching goal is to restore or change the assemblage's so as to render it performative again. This performative exigency therefore speaks to the guiding principle by which assemblages changed, evolved, and stabilized. We also point out that the performative exigency reflects a post-humanist perspective in that this guiding principle is not so much driven by heroic individuals or coalitions as it is determined and shaped by the network of relations among the different components [42].

\subsection{Consequences of Sociomaterial Change - Transformed Accountability}

Our findings on stratifying and how the different assemblages changed with the new EMR system also highlighted a surprising and important consequence of their new performances i.e., new forms of accountability. This finding resonates with emerging stream of research on discursive materiality [5]. Specifically, this stream of research argues that the inclusion of a technological artifact does not simply improve an assemblage's performance, it could potentially transform the performances of the assemblage as well. In the case of Scott and Orlikowski's [5] study of the TripAdvisor's ranking mechanism, they show that the mechanism did not just make travel information easier but actually actively performed new ways by which online travellers make sense of hotel information. Likewise, in our study, the EMR system did not just changed the way different practices were performed as we have described, it actually performed a new sense of accountability among the different groups of actors across the two clinics. In other words, as pointed out by Orlikowski and Scott [4] in their seminal piece on sociomateriality, we find that changes in sociomaterial assemblages have significant consequences on organizing and work. This adds to the extant literature that includes Barley's [43] seminal piece on how the use of CT scanners changed roles in radiology departments to a recent study by Barrett et al. [31] on the changes 
in work boundaries within pharmacies due to the use of a dispensing robot. The difference in our case was that the technology did not indirectly lead to those organizational changes; instead the fundamental change in how accountability was performed was the direct result of the technologies' performances.

As we have discussed above, the new accountability emerged given how the EMR system informates and make visible information across the assemblages [44]. The EMR system has also mediated and linked components that previously were not as "close". For example, in lab resulting, the medical assistants' work is much more closely linked to the physicians' work because of the new EMR lab resulting system. The tighter mediation of different parts of assemblages through the EMR system therefore catalyzed the performance of new accountability [45].

More importantly, and closer to the notion of "accountability" is that the new sociomaterial assemblage has created new ways of measuring performance to support evaluation and accountability, as well as, the allocation of responsibility [29, pp. 581582]. The EMR in the new assemblages as discussed in the findings now renders each of the components as measurable, comparable and thus auditable (e.g. the output reports). Thus our findings show that medical assistants could track and see if the doctors have completed their in basket messages so that they can close their cases and vice versa for the physicians. In sum the performance of the EMR as part of the new assemblages led to a new configuration of relationships through its mediation and rendering of components measurable and comparable. These in turn helped to reconfigure new performances of accountability.

\section{References}

1. Zammuto, R., Griffith, T., Majchrzak, A., Dougherty, D., Faraj, S.: Information Technology and the Changing Fabric of Organization. Organization Science 18(5), 749-762 (2007)

2. Leonardi, P.M., Nardi, B.A., Kallinikos, J.: Materiality and Organizing Social Interaction in a Technological World. Oxford University Press, Oxford (2012)

3. Orlikowski, W.J.: The Sociomateriality of Organisational Life: Considering Technology on Management Research. Cambridge Journal of Economics 34(1), 125-141 (2010)

4. Orlikowski, W., Scott, S.: Sociomateriality: Challenging the Separation of Technology, Work and Organization. Academy of Management Annals 2(1), 433-474 (2008)

5. Scott, S., Orlikowski, W.: Reconfiguring Relations of Accountability: Materialization of Social Media in the Travel Sector. Accounting, Organizations and Society 37, 26-40 (2012)

6. Faraj, S., Azad, B.: The Materiality of Technology: An Affordance Perspective. In: Leonardi, P.M., Nardi, B., Kallinikos, J. (eds.) Materiality and Organizing: Social Interaction in a Technological World, pp. 237-258. University of Michigan Press (2012)

7. DeLanda, M.: A New Philosophy of Society: Assemblage Theory and Social Complexity. Continuum (2006)

8. Callon, M.: What Does It Mean to Say that Economics Is Performative? In: MacKenzie, D., Muniesa, F., Siu, L. (eds.) Do Economists Make Markets? On the Performativity of Economics, pp. 310-357. Princeton University Press (2007)

9. MacKenzie, D., Muniesa, F., Siu, L.: Do Economists Make Markets? On the Performativity of Economics. Princeton University Press (2007)

10. Deleuze, G., Guattari, F.: What Is Philosophy? Columbia University Press (1994) 
11. Barad, K.: Posthumanist Performativity: Toward an Understanding of How Matter Comes to Matter. Signs 28(3), 801-831 (2003)

12. Kautz, K., Jensen, T.B.: Sociomateriality at the Royal Court of IS. Information and Organization 23(1), 15-27 (2013)

13. Leonardi, P.: Theoretical Foundations for the Study of Sociomateriality. Information and Organization 23(2), 59-76 (2013)

14. Leonardi, P., Barley, S.: Materiality and Change: Challenges to Building Better Theory about Technology and Organizing. Information and Organization 18(3), 159-176 (2008)

15. Leonardi, P.: When Flexible Routines Meet Flexible Technologies: Affordance, Constraint, and the Imbrication of Human and Material Agencies. MIS Quarterly 35(1), 147-167 (2011)

16. Pickering, A.: The Mangle of Practice: Agency and Emergence in the Sociology of Science. American Journal of Sociology 99(3), 559-589 (1993)

17. Callon, M., Muniesa, F.: Economic Markets as Calculative Collective Devices. Organization Studies 26(8), 1229-1250 (2005)

18. Law, J., Singleton, V.: Performing Technology's Stories: On Social Constructivism, Performance, and Performativity. Technology and Culture 41(4), 765-775 (2000)

19. Knorr-Cetina, K.: Tinkering toward Success: Prelude to a Theory of Scientific Practice. Theory and Society 8, 347-376 (1979)

20. Riemer, K., Johnston, R.S.: Place-Making: A Phenomenological Theory of Technology Appropriation. In: ICIS 2012 Proceedings (2012), http://aisel.aisnet.org/ icis2012/proceedings/Socialimpacts/5/

21. Nicolini, D.: The Work to Make Telemedicine Work: A Social and Articulative View. Social Science \& Medicine 62(11), 2754-2767 (2006)

22. Fujimura, J.: Crafting Science: A Sociohistory of the Quest for the Genetics of Cancer. Harvard University Press (1996)

23. Law, J.: On the Methods of Long-Distance Control: Vessels, Navigation and the Portuguese Route to India. In: Law, J. (ed.) Power, Action and Belief: A New Sociology of Knowledge, pp. 234-263. Routledge and Keegan, London (1986)

24. Oborn, E., Barrett, M., Davidson, E.: Unity in Diversity: Electronic Patient Record Use in Multidisciplinary Practice. Information Systems Research 22(3), 547-564 (2011)

25. Yin, R.: Case Study Research: Design and Methods. Sage (2003)

26. Schatzki, T.R.: Introduction: Practice Theory. In: Schatzki, T.R., Knorr-Cetina, K., von Savigny, E. (eds.) The Practice Turn in Contemporary Theory, pp. 10-23. Routledge (2001)

27. National Committee for Quality Assurance (NCQA): Standards and Guidelines for Physician Practice Connections - Patient-Centered Medical Home (PPC-PCMH). National Committee for Quality Assurance (NCQA), Washintgon, DC (2008)

28. Charmaz, K.: Constructing Grounded Theory: A Practical Guided Through Qualitative Analysis, 3rd edn. Sage (2006)

29. Miller, P., Power, M.: Accounting, Organizing, and Economizing. Academy of Management Annals 7(1), 555-603 (2013)

30. Scott, S., Orlikowski, W.: Sociomateriality - Taking the Wrong Turning? A Response to Mutch. Information and Organization 23(2), 77-80 (2013)

31. Barrett, M., Oborn, E., Orlikowski, W., Yates, J.: Reconfiguring Boundary Relations: Robotic Innovations in Pharmacy Work. Organization Science 23(5), 1448-1466 (2012)

32. Kjellberg, H.: The Death of a Salesman? Reconfiguring Economic Exchange in Swedish Post-War Food Distribution. In: Callon, M., Millo, Y., Muniesa, F. (eds.) Market Devices, pp. 65-91. Blackwell, Malden (2007) 
33. Hanseth, O., Braa, K.: Hunting for the Treasure at the End of the Rainbow: Standardizing Corporate IT Infrastructure. Computer Supported Cooperative Work 10(3/4), 261-292 (2001)

34. Hanseth, O., Monteiro, E., Hatling, M.: Developing Information Infrastructure: The Tension between Standardization and Flexibility. Science, Technology, \& Human Values 21(4), 407-426 (1996)

35. Star, S., Ruhleder, K.: Steps Toward an Ecology of Infrastructure: Design and Access for Large Information Spaces. Information Systems Research 7(1), 111-134 (1996)

36. Phillips, N., Oswick, C.: Organizational Discourse: Domains, Debates, and Directions. Academy of Management Annals 6(1), 435-481 (2012)

37. Leonardi, P., Barley, S.: What's Under Construction Here? Social Action, Materiality, and Power in Constructivist Studies of Technology and Organizing. Academy of Management Annals 4(1), 1-51 (2010)

38. Orlikowski, W.: Improvising Organizational Transformation over Time: A Situated Change Perspective. Information Systems Research 7(1), 63-92 (1996)

39. Ciborra, C.: From Control to Drift. Oxford Publishing Press (2000)

40. Latour, B.: Pandora's Hope: Essays on the Reality of Science Studies. Harvard University Press, Cambridge (1999)

41. Jones, M.: Information Systems and the Double Mangle: Steering a Course between the Scylla of Embedded Structure and the Charybdis of Strong Symmetry. In: Larsen, T.J., Levine, L., DeGross, J. (eds.) Information Systems: Current Issues and Future Changes, pp. 287-302. IFIP Press (1998)

42. Millo, Y.: Making Things Deliverable: The Origins of Index-Based Derivatives. In: Callon, M., Millo, Y., Muniesa, F. (eds.) Market Devices, pp. 196-214. Blackwell, Malden (2007)

43. Barley, S.: Technology as an Occasion for Structuring: Evidence from Observations of CT Scanners and the Social Order of Radiology Departments. Administrative Science Quarterly 31(1), 78-108 (1986)

44. Zuboff, S.: In the Age of the Smart Machine: The Future of Work and Power. Basic Books (1988)

45. D'Adderio, L.: The Performativity of Routines: Theorising the Influence of Artefacts and Distributed Agencies on Routines Dynamics. Research Policy 37(5), 769-789 (2008) 